\title{
A study of tea leaves drying using dehumidification process and regeneration of liquid desiccant in a closed-cycle dehumidification-humidification
}

\author{
Eflita Yohana, ${ }^{1, *}$, Mohammad Endy Yulianto ${ }^{2}$, Shofwan Bahar $^{1}$, Azza Alifa Muhammad ${ }^{1}$, \\ and Novi Laura Indrayani ${ }^{3}$ \\ ${ }^{1}$ Department of Mechanical Engineering, Faculty of Engineering, Diponegoro University, 50275 \\ Semarang, Indonesia \\ ${ }^{2}$ Department of Industrial Technology, Faculty of Engineering, Diponegoro University, 50275 \\ Semarang, Indonesia \\ ${ }^{3}$ Department of Mechanical Engineering, Faculty of Engineering, Islamic 45 University, 17113 \\ Bekasi, Indonesia
}

\begin{abstract}
Tea plants in Indonesia are derived from Carmelia sinensis var. assamica which contain catechin in quite high amount compared with other countries tea plant. Green tea is made by inactivating the oxidase / phenolase enzyme that presents in the fresh tea leaf buds from tea garden, by using hot steam to prevent the oxidation of the catechins. Drying process to reduce the moisture of tea, one of the method is by utilizing the dry air from dehumidification process. Liquid desiccant made from $50 \%$ concentration of $\mathrm{CaCl}_{2}$, the temperature is lowered to $10{ }^{\circ} \mathrm{C}$ and sprayed into the air stream which contains water vapor by using a $0.2 \mathrm{~mm}$ spraying nozzle so that mass transfer and latent heat occur in the dehumidifier. The result of air dehumidification process used for drying tea leaves. The air is able to dry the tea leaves from the weight of 58 grams to 47 grams. Then the liquid desiccant dehumidification process will be streamed into the humidifier, where the liquid desiccant regeneration process will have change into the initial concentration. The result of air humidification process has an average absolute humidity rise of $0.07 \mathrm{~g} / \mathrm{kg}$. The liquid desiccant regeneration process that happened continuously reaching the saturation point at 280 minutes. It can be concluded that the process of dehumidification-humidification is a fairly effective method for drying the tea leaves.
\end{abstract}

\section{Introduction}

Indonesia is a country that has a great wealth of biodiversity, there are approximately 30,000 species of plants that grow in Indonesia [1], which includes the tea plant. Tea plants with Camellia sinensis varieties assamica in Indonesia have a high enough catechin content

* Corresponding author: efnan2003@gmail.com 
rather than other tea plants. Green tea is made by inactivates the enzyme oxidase / phenolase present in the fresh tea leaf buds of the tea garden with using hot steam so that oxidation of the catechins can be prevented. Hot steam which used for tea leaves should have a temperature between $80{ }^{\circ} \mathrm{C}-100{ }^{\circ} \mathrm{C}$ [2]. Furthermore, the tea will undergo a drying process to reduce the water content in the tea leaves.

In the process of drying the tea leaves, temperature and humidity are two things that are important to note. Moist air can inhibit the drying process of the tea leaves and will trigger the growth of bacteria that can be harmful to human life. But if the air is too dry, it will cause some problems, such as case hardening and a condition which the outside of the tea leaves is dry but the inside is still moist. This will cause the growth of mushrooms on the tea leaves [3].

Today research on the air conditioning system has been growing rapidly. There is an alternative to air conditioning systems that are air conditioning system with desiccant as a working fluid. Desiccant has hygroscopic properties, which can absorb water vapor contained in the air. The selection of desiccant as the working fluid in the air conditioning system has some advantages, that is able to achieve low humidity, energy saving and environmentally friendly [4].

The process of reduction of water vapor in the air is called dehumidification process. This process uses low temperature between $22{ }^{\circ} \mathrm{C}-25^{\circ} \mathrm{C}$, so there is no oxidation in the tea leaves and the color of the tea leaves still green. After that, a desiccant is sprayed into the air stream containing water vapor which results from mass transfer and latent heat. During the process of absorption of water vapor, sorbent, known as the desiccant liquid reaches a point where the ability of moisture absorption of liquid desiccant will be decreased. To be able to be reused, the liquid desiccant must be regenerated [5]. The tools to regenerate the desiccant liquid called a regenerator or commonly known Humidifier. The working principle of the tools is to eliminate the moisture content in the liquid desiccant, which can be done by heating the liquid desiccant to revert it to original concentration [6].

\section{Materials and methods}

Liquid desiccant is made by dissolving $\mathrm{CaCl}_{2}$ using distilled water with a concentration ratio of $50 \%: 50 \%$. This data is collected until the condition of the inlet sample side of the house shows that there are no changes in temperature and humidity or in another word, the sample condition is already as steady as it is. The drying process of tea leaves itself is done by conducting the steaming and rolling process.

The desiccant liquid sampling performs every 20 minutes during the process of dehumidification and regeneration/humidification takes place, namely when the desiccant liquid has a before and after contact with both the dehumidifier and air humidifier.

Scheme research tool in Figure 1 consists of a dehumidifier, humidifier, pumps, chillers, nozzle $0.2 \mathrm{~mm}$, the sensor DHT 11 , and $\mathrm{CaCl}_{2}$ with a concentration of $50 \%$ as its liquid desiccant.

Using mass and energy balance can calculate dry air for dehumidifying or humidifying

$$
\dot{\boldsymbol{m}}_{a}=\frac{\dot{\boldsymbol{m}}_{1}\left(\boldsymbol{h}_{f 1}-\boldsymbol{h}_{f 2}\right)}{\left(\boldsymbol{h}_{g 4}+\omega_{4} \boldsymbol{h}_{g 4}\right)-\left(\boldsymbol{h}_{a 3}+\omega_{3} \boldsymbol{h}_{g 3}\right)}
$$




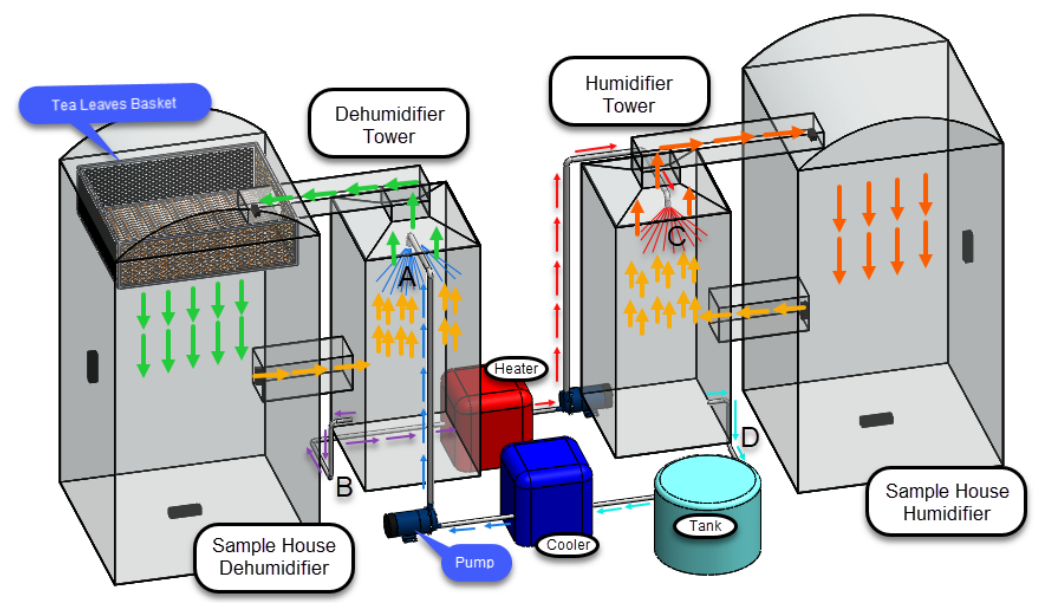

Fig. 1. Analysis tool scheme.

The study was conducted by cooling the desiccant liquid until it can reach a temperature of $10{ }^{\circ} \mathrm{C}$ from cooler, and air flow rate of $2.35 \mathrm{~m}^{3} / \mathrm{min}$ (without any eliminator) from sample house dehumidifier. In the dehumidifier, the liquid desiccant will be sprayed using a spraying nozzle that has an outlet hole of $0.2 \mathrm{~mm}$ and at the same time, the air from sample house dehumidifier will be dry, then the dry air has through pass tea leave basket and remove the moisture content of tea leaves. After the liquid desiccant is sprayed in dehumidifier will be accommodated and fed to the humidifier. Furthermore, liquid desiccant will be going through a regeneration process by raising the temperature from a heating process to heat temperature of $70{ }^{\circ} \mathrm{C}$. In the humidifier, liquid desiccant will be sprayed using a spraying nozzle and then there will be liquid desiccant regeneration process to bring back its original concentration. The occurring changes in humidity and air temperature within the sample house will be read by the sensor DHT 11 that is mounted on four sides, which are at the inlet, the walls, floors, and outlets in the sample house. The use of closed system method considered because less energy consumption throughout the process than if we use open system method.

\section{Result and discussion}

\subsection{The result drying the tea leaves in dehumidification/humidification process}

The results of the study will be compared to the international journal which the result of this research was the dry air is the element that is used to dry the leaves. The referenced journal that is used for this comparison is the research conducted by Jun Liu, et al. Beijing Tsinghua University of China in 2015. In June, this research analyzed the results of the research where dehumidification/humidification regeneration is made of a thermally conductive plastic using a liquid desiccant.

In Jun Liu's study, it used lithium bromide $(\mathrm{LiBr})$ as liquid desiccant with a concentration rate of 38.8 to $42.2 \%$, and with a temperature rate of 28.6 to $31.5^{\circ} \mathrm{C}$. Jun Liu, et al. also used additional components such as pipes that drained the water used for the cooling medium air passing through the dehumidifier with a water temperature of 11.1 to $17.0^{\circ} \mathrm{C}$, as well as the heating medium air that passed through the regenerator with a water temperature of 31.1 to $41,8{ }^{\circ} \mathrm{C}$. 


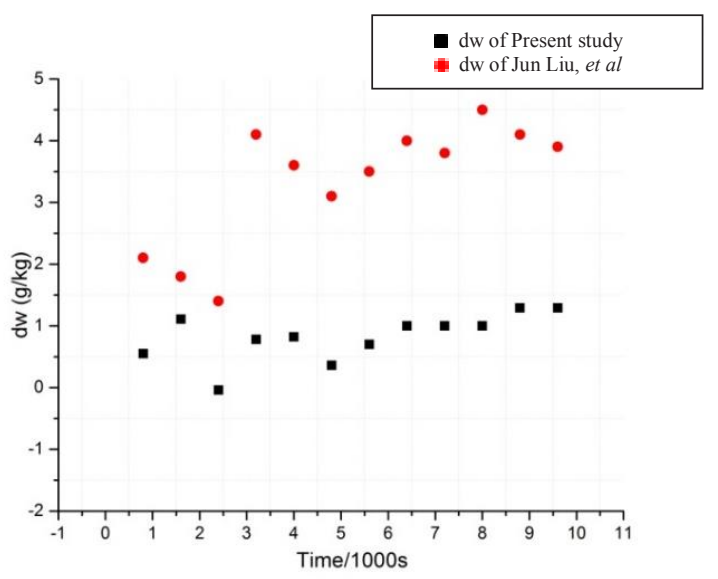

Fig. 2. Comparison of absolute moisture reduction in dehumidification process every 1000 seconds.

When compared to the results of research conducted by Jun Liu, et al. in Figure 2 which has the ability to decrease the average absolute humidity of $3.3 \mathrm{~g} / \mathrm{kg}$, the dehumidification tool used in this research still have not achieved the capability yet because it has the ability to decrease the average absolute humidity of $0.78 \mathrm{~g} / \mathrm{kg}$. The main cause of the difference between the results of the Jun Liu, et al. study and the results of this current study is due to the different liquid desiccant that was used are $\mathrm{LiBr}$ and $\mathrm{CaCl}_{2}$.

The result of the research conducted by Koronaki, et al (2012) on the analysis of thermodynamics in a dehumidifier adiabatic with the type of flow counter flow using different materials, there were namely $\mathrm{LiCl}, \mathrm{LiBr}$, and $\mathrm{CaCl}_{2}$ posed as liquid desiccant her, stating that $\mathrm{LiBr}$ has the ability to reduce the humidity more nicely compared to $\mathrm{CaCl}_{2}$. This study decided to use $\mathrm{CaCl}_{2}$ which safer to consume than $\mathrm{LiBr}$. Although $\mathrm{CaCl}_{2}$ decrease possibility of humidity will not as good as LiBr.

In the study of Jun Liu, et al. (2015), it used lithium bromide ( $\mathrm{LiBr}$ ) as its liquid desiccant with a concentration of 38.8 to $42.2 \%$ a temperature of 28.6 to $31.5{ }^{\circ} \mathrm{C}$. Jun Liu, et al. also used additional components such as pipes that drained the water used for the cooling medium air passing through the humidifier with a water temperature of 11.1 to 17.0 ${ }^{\circ} \mathrm{C}$, as well as the heating medium air that passed through the regenerator with a water temperature of 31.1 to $41,8{ }^{\circ} \mathrm{C}$.

When compared to the results of experiments conducted by Jun Liu, et al. (2015), which has an average ability to increase the absolute humidity value of $3.2 \mathrm{~g} / \mathrm{kg}$, the regenerator that we use still cannot achieve the right capability since it only has the ability to increase the average absolute humidity values of $0.07 \mathrm{~g} / \mathrm{kg}$. 


\subsection{The weight decrease of tea leaves during the drying process by dehumidification process air}

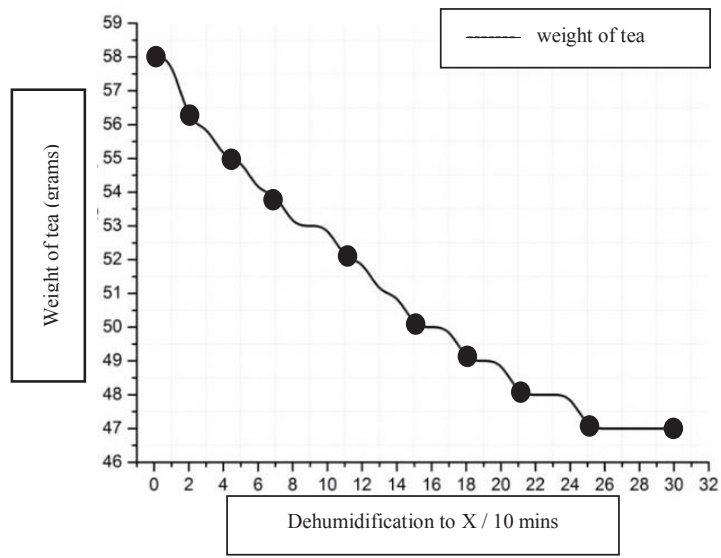

Fig. 3. Graph of tea leaf weight loss during drying process by dehumidification process air.

In Figure 3, it is known that the early tea weight was 58 grams. The weighing is done every 10 minutes during the drying process takes place. It can be seen that the weight loss tea leaves in early weighing less constant over 2 times the weighing (20 minutes) on average by 1 gram and ends on the state of constant weight by 47 grams for 6 times the weighing (1 hour) with the time needed to achieve weight ie constant for 25 times the weighing (4 hours, 10 minutes). This shows that the dry air dehumidification process results capable of drying the tea leaves from the weight of 58 grams to 47 grams, was reduced by 11 grams within 5 hours.

\subsection{Changes in liquid desiccant concentration during humidification process}
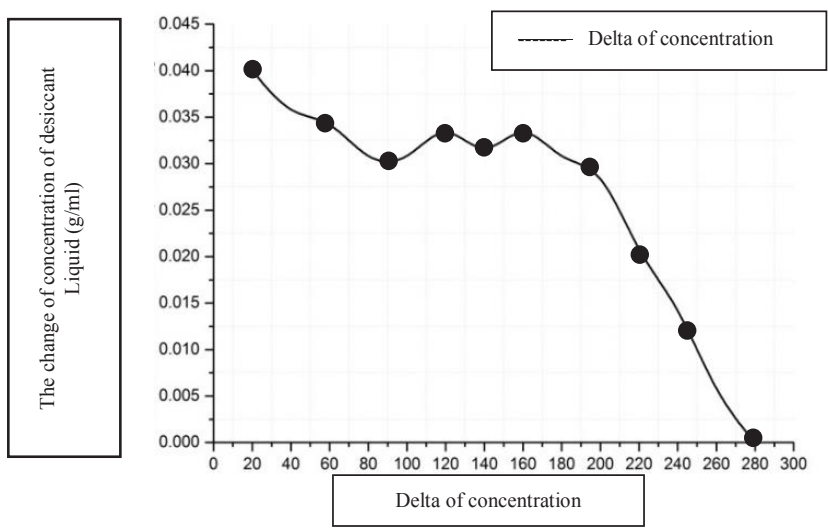

Fig. 4. Graph of change of liquid desiccant concentration humidification process.

In Figure 4, it can be seen that there is a decrease in the concentration of liquid desiccant which is significant at the $200^{\text {th }}$ minute or 1 hour 20 minutes. And at $280^{\text {th }}$ minutes, there is no decline in the concentration of liquid desiccant. This proves that the liquid desiccant has already experienced a saturation point where the rate of moisture absorption comes from the liquid desiccant down. If absorption rate of the air remains stable needed, using another type of liquid desiccant is recommend. 


\section{Conclusions}

The result of air dehumidification process for tea leaves drying process has relative humidity degradation value of $11 \%$ with absolute humidity steady degradation value of 1 $\mathrm{g} / \mathrm{kg}$ and has the capability to reduces 11 grams tea leaves from 58 grams to 47 grams of weight. The result of air humidification process shows absolute humidity increment value of $0.07 \mathrm{~g} / \mathrm{kg}$. As can be seen, dry air in the humidifier absorbs water vapor in the liquid desiccant which is evidenced by a significant decrease in the concentration of liquid desiccant in the $200^{\text {th }}$ minute or 1 hour 20 minutes and at $280^{\text {th }}$ minutes there is no more decline in the concentration of liquid desiccant.

\section{Nomenclature}

\begin{tabular}{llll}
\multicolumn{1}{c}{ Symbol } & & \multicolumn{1}{c}{ Description } & Unit \\
$\dot{m}_{a}$ & $:$ & Flow rate of the dry air & $\mathrm{Kg} / \mathrm{h}$ \\
$\dot{m}_{1}$ & $:$ & Flow rate of $\mathrm{CaCl}_{2}$ & $\mathrm{Kg} / \mathrm{h}$ \\
$h_{f 1}$ & $:$ & Specific enthalpy of $\mathrm{CaCl}_{2}$ & $\mathrm{Kj} / \mathrm{Kg}$ \\
$h_{f 2}$ & $:$ & Specific enthalpy of air & $\mathrm{Kj} / \mathrm{Kg}$ \\
$h_{a 3}$ & $:$ & Enthalpy of atmospheric air & $\mathrm{Kj} / \mathrm{Kg}$ \\
$h_{a 4}$ & $:$ & Enthalpy of CaCl & $\mathrm{Kj} / \mathrm{Kg}$ \\
$\omega_{3}$ & $:$ & Humidity ratio of atmospheric air & - \\
$\omega_{4}$ & $:$ & Humidity ratio of CaCl & -
\end{tabular}

\section{References}

1. D. Handayani, A. Mun'im, A.S. Ranti, Optimasi ekstraksi ampas teh hijau (camellia sinensis) menggunakan metode microwave assisted extraction untuk menghasilkan ekstrak teh hijau. Tradisional medicine Journal, 19(1), 29-35 (2014)

2. E. Yohana, M.S.K.T.S. Utomo, T. Ivantoro, Z. Arifin, M. Tauviqirrahman, Effect of Temperature and Relative Humidity on the Performance of Steamer using Computational Fluid Dynamic (CFD). International Journal of Engineering and Technology (IJET), 8 (4), 1737-1749 (2016)

3. E. Yohana, M.E. Yulianto, M.A. Dwisukma, Pengembangan teknik dehumidifikasi absorbsi pada fluidized bed dryer untuk produksi teh hijau kaya polifenol. Semarang: s.n (2015)

4. J. Liu, T. Zhang, X. Liu, J. Jiang, Experimental analysis of an internally-cooled/heated liquid desiccant dehumidifier/regenerator made of thermally conductive plastic. Energy and Buildings, 99, 75-86 (2015)

5. E. Yohana, C.K. Hwan, Prediction on heat and mass transfer coefficients in a packed layer of a regenerator with a solar desiccant cooling system. Journal of the Korean Solar Energy Society, 30, 4 (2010)

6. Y. Yonggao, X. Zhang, D. Peng, X. Li, Model validation and case study on internally cooled/heated dehumidifier/regenerator of liquid desiccant systems. International Journal of Thermal Sciences, 48, 1664-1671 (2009) 